\title{
Fabrication of Planar Power Inductor for Embedded Passives in LSI Package for Hundreds Megahertz Switching DC-DC Buck Converter
}

\author{
Hideyuki Ito ${ }^{1}$, Asako Takeuchi ${ }^{2}$, Shinya Okazaki ${ }^{1}$, Hiroki Kobayashi ${ }^{1}$, Yuichiro Sugawa ${ }^{1}$, Akihiro Takeshima ${ }^{1}$, \\ Makoto Sonehara ${ }^{1}$, Nobuhiro Matsushita ${ }^{2}$, Toshiro Sato ${ }^{1}$ \\ ${ }^{1}$ Spin Device Technology Center, Shinshu University, Nagano 380-8553, Japan \\ ${ }^{2}$ Materials and Structures Laboratory, Tokyo Institute of Technology, Yokohama 226-8503, Japan
}

Recently, research and development of integrated low-voltage DC-DC converter to LSIs has been active. In order to realize such integrated de power supply, power magnetic devices must be integrated in it. The authors have fabricated planar power inductor embedded in LSI package for hundreds megahertz switching dc-dc buck converter. In this study, two types of planar power inductors have been fabricated, one was spin-sprayed $\mathrm{Zn}$-ferrite thick film magnetic core inductor, the other was composite magnetic core (Febased amorphous/polyimide) inductor. Foot-print of the fabricated inductors was $850 \mathrm{X850} \mu \mathrm{m}$, their inductance was about $10 \mathrm{nH}$ and quality factor $Q$ was about 20 at $100 \mathrm{MHz}$. The rating current which depends on the superimposed de current characteristic was at least up to $2 \mathrm{~A}$.

Index Terms-Planar power inductor, Zn-ferrite thick film core, Fe-based amorphous/polyimide composite core, embedded passives, LSI package, dc-dc converter

\section{INTRODUCTION}

$\mathrm{M}$ ANY researchers reported the high-frequency planar magnetic devices and their application to micro switching DC-DC converter [1]-[5]. Also, various on-chip magnetic thin film inductors for RF applications were reviewed by D. S. Gardner et al. [6]. In order to apply such planar magnetic device as a power device to dc-dc converter, it should have the following features; a low production-cost (foot-print as small as possible: large inductance density per unit area, higher operating frequency), a higher $Q$-factor (large inductance and low loss at high-frequencies), small dc copper-loss ( $\mathrm{dc}$ coil resistance as low as possible), and a large rating current (excellent superimposed dc current characteristic; large saturation magnetic field of the magnetic core). The authors think it is not so easy to apply the soft magnetic thin film to power magnetic devices, because it is difficult to obtain large magnetic core cross-section for obtaining large inductance and large rating current without increase of production cost.

On the other hand, recently, research and development of the integrated low-voltage/large-current DC-DC converter to LSIs has been active [7], [8], where in order to obtain small foot-print of magnetic device, very high switching frequency around hundreds megahertz has been selected. P. Hazucha et al. reported a $233 \mathrm{MHz}$ switching 4-phase buck DC-DC converter chip developed by using $90 \mathrm{~nm}$ CMOS process [7], where four air-core chip inductors on package were used. Although thick coil air-core inductor has large rating current and small loss, undesired local EMI noise owing to the leakage magnetic flux will influence on the electronic circuit operation in LSI. Therefore, to suppress the EMI noise, magnetic core should be used for integrated power inductor.

This study focuses on a possibility of the planar power

Manuscript received February 21, 2011, revised XXXX, 2011. Corresponding author: T. Sato (e-mail:sato@yslab.shinshu-u.ac.jp). inductor embedded in LSI package for hundreds megahertz switching DC-DC converter. A block diagram of the integrated power supply with power inductor and capacitor embedded in LSI package is shown in Fig. 1. Since the current LSI package process consists of metallization for distributed conductor line and interlayer insulation, the planar power inductor will be embedded in package by introducing magnetic core fabrication to package process.

In this study, in order to investigate the application of $\mathrm{Zn}$ ferrite thick film and Fe-based amorphous/polyimide composite thick film to the planar power inductor, planar power inductors have been fabricated using two kinds of magnetic cores, and their electrical properties have been evaluated.

\section{MAgnetic Core AND PlanAR POWER INDUCTOR}

\section{A. Magnetic core materials for planar power inductor}

In this study, two types of magnetic core materials were used for planar power inductor, one was spin-sprayed Znferrite thick film magnetic core, and the other was Fe-based amorphous/polyimide composite core. $\mathrm{Zn}$-ferrite thick film $\left(\mathrm{Zn}_{0.36} \mathrm{Fe}_{2.64} \mathrm{O}_{4}\right)$ was made by spin-spray method [9], [10]. Fe-

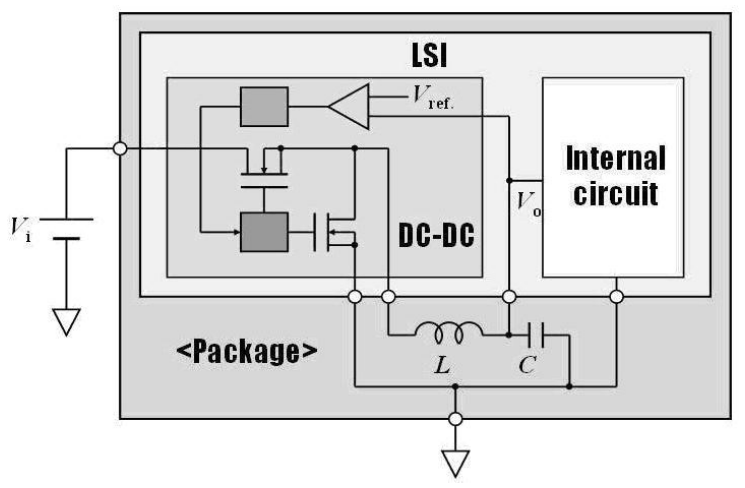

Fig. 1 Inductor embedded in LSI package for dc-dc converter. 


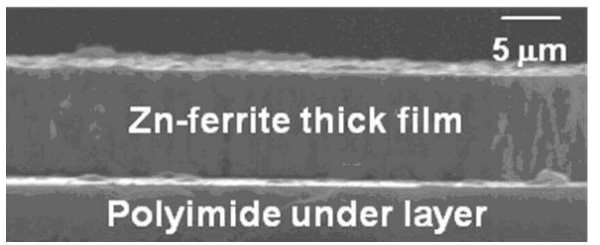

(a)Zn-ferrite thick film

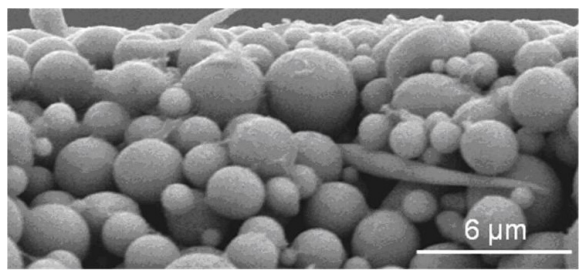

(b) Fe-based amorphous/polyimide composite thick film

Fig. 2 Cross-section of thick magnetic core used for planar power inductor. (a) Static magnetization curve

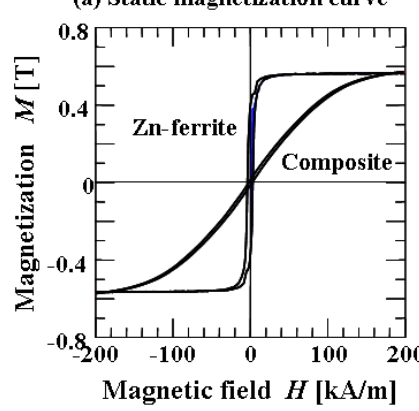

(b) Permeability v.s. frequency

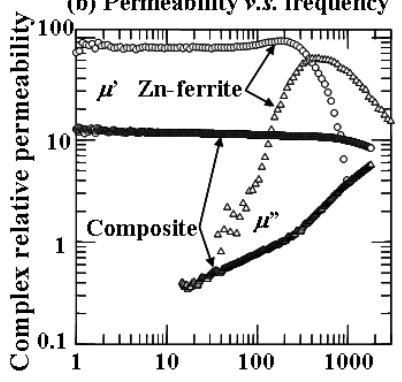

Frequency $f[\mathrm{MHz}]$
Fig. 3 Magnetic properties of $10 \mu \mathrm{m}$ thick $\mathrm{Zn}$-ferrite film and 35 $\mu \mathrm{m}$ thick 50 vol.\% Fe-based amorphous/polyimide composite film, (a) : static magnetization property, (b) : complex permeability v.s. frequency. based amorphous/polyimide composite thick film made by screen-printing consisted of 50 vol.\% Fe-Si-B-Cr amorphous particles [11] and polyimide binder.

Fig. 2 shows the cross-sectional view of $10 \mu \mathrm{m}$ thick $\mathrm{Zn}$ ferrite thick film and $35 \mu \mathrm{m}$ thick Fe-based amorphous/ polyimide composite thick film. Since the $\mathrm{Zn}$-ferrite film can be deposited through the low temperature of 90 degree-C [9], it was easy to obtain a patterned structure using photo-resist lift-off process. Fe-Si-B-Cr amorphous particle [11] with a thin $\mathrm{SiO}_{2}$ surface layer had a mean diameter of $2.6 \mu \mathrm{m}$ and saturation magnetization of $1.2 \mathrm{~T}$. The magnetic paste with magnetic particles and polyimide precursor solution was printed using screen mask and then was fired at 300 degree-C in temperature.

Since two thick magnetic cores can be fabricated without using expensive machines such as sputtering apparatus, the production cost will be reduced.

\section{B. Magnetic properties of core materials}

Fig. 3 shows the typical magnetic properties of $10 \mu \mathrm{m}$ thick $\mathrm{Zn}$-ferrite film and $35 \mu \mathrm{m}$ thick 50 vol.\% Fe-based amorphous composite film, (a) is the static magnetization curve measured by using vibrating sample magnetometer (BHV-55; Riken Denshi Co.), and (b) is the complex permeability measured by using coaxial method for toroidal composite sample and thin film permeameter method [12] for Zn-ferrite sample.

In the static magnetization properties shown in Fig. 3(a), saturation magnetization of $\mathrm{Zn}$-ferrite core was $0.57 \mathrm{~T}$, and that of composite core was $0.61 \mathrm{~T}$. The composite core had the diluted magnetization and had low permeability magnetization curve.

In the complex permeability v.s. frequency shown in Fig. 3 (b), the low frequency relative permeability of $\mathrm{Zn}$-ferrite core was 80 , and that of composite core was 11 . Zn-ferrite core had a natural resonance frequency of $500 \mathrm{MHz}$. Such higher natural resonance frequency may be due to the

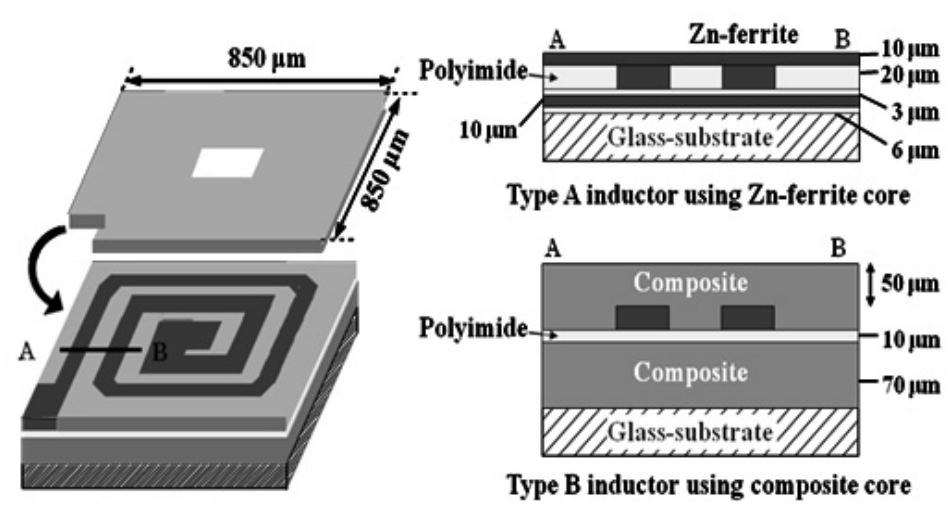

(a) Schematic view
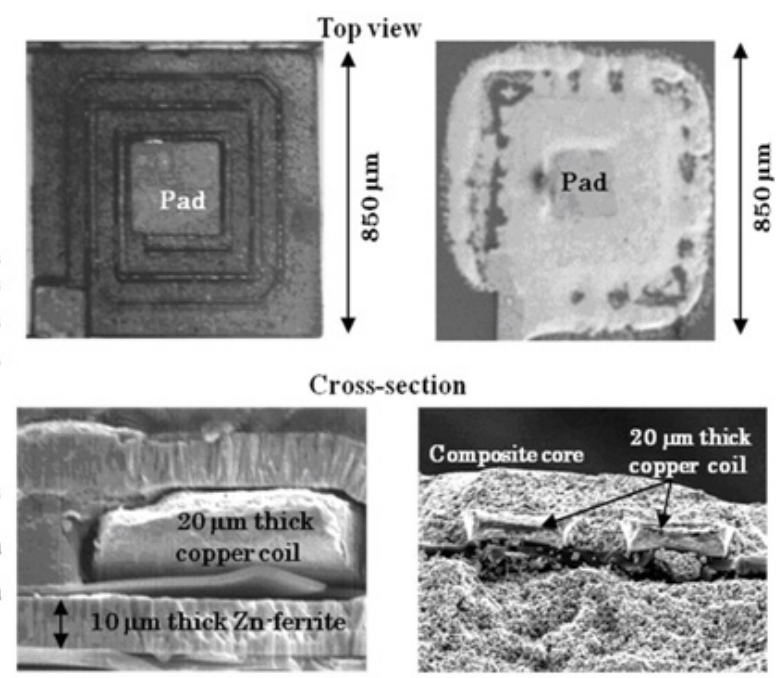

Type A inductor

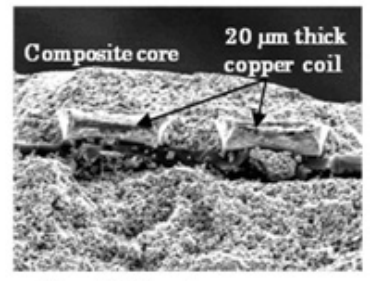

Type B induc tor

(b) Photograph

Fig. 4 Schematic view and photograph of fabricated planar power inductors using Zn-ferrite thick film core and 50 vol.\% Fe-based amorphous/polyimide composite thick film core. 


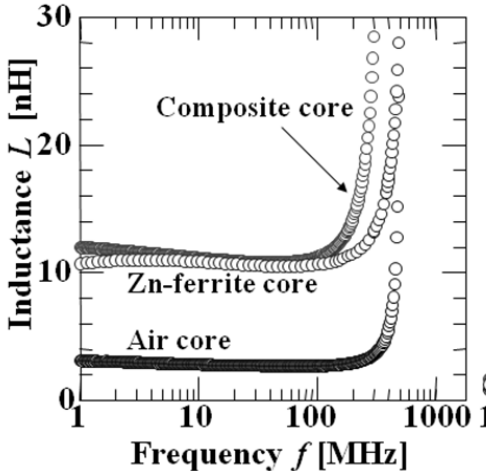

(a) Inductance and quality factor v.s. frequency

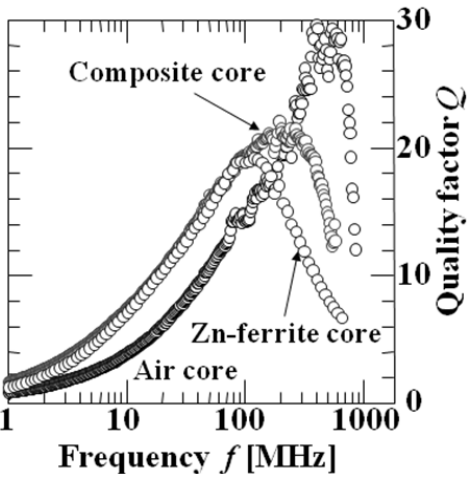

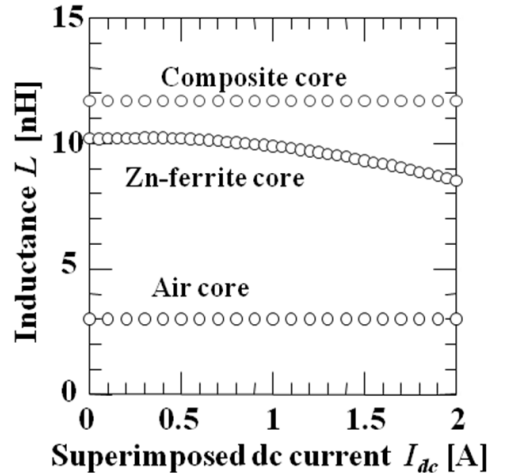

Superimposed dc current $I_{d c}[\mathrm{~A}]$
end dc current characteristic of inductance

Fig. 5 Electrical properties of fabricated planar power inductors.

magnetization aligned in the film plane by demagnetizing field perpendicular to the film plane. The loss tangent $(\tan \delta)$ of both magnetic cores was small enough at around $100 \mathrm{MHz}$.

\section{Inductor structure and fabrication method}

Fig. 4 shows the schematic view and photograph of the fabricated planar power inductors using two kinds of core materials. The inductors with a footprint of 850 X850 $\mu \mathrm{m}$ had a structure consisting of top and bottom outer magnetic core and an inner $650 \mu \mathrm{m}$-square, 2-turn square spiral coil. Target inductance, quality factor and rating superimposed dc current were $10 \mathrm{nH}$, over 20 at $100 \mathrm{MHz}$, and $2 \mathrm{~A}$, respectively.

Spin-sprayed $10 \mu \mathrm{m}$ thick $\mathrm{Zn}$-ferrite film core was used for Type A inductor with a open magnetic circuit. Thicker magnetic core gives a larger rating current. However, it was hard to obtain $\mathrm{Zn}$-ferrite film with over $10 \mu \mathrm{m}$ thickness because of undesired film removal from underlayer owing to the internal film stress.

Since the composite magnetic core had lower permeability than that of $\mathrm{Zn}$-ferrite core, Type B inductor consisted of thicker composite magnetic core (top core thickness; $50 \mu \mathrm{m}$, bottom core thickness; $70 \mu \mathrm{m}$ ) and a closed magnetic circuit. When the top core was made by screen-printing, the composite paste was not only printed on the top of coil conductor line but also filled in the spacing between conductor lines. Therefore the top composite core thickness became smaller than that of bottom core fabricated on the flat surface.

Inner 2-turn spiral coil with $20 \mu \mathrm{m}$ thickness and 50/40 $\mu \mathrm{m}$ line/space was made by copper electroplating, and it had a dc resistance of $50 \mathrm{~m} \Omega$.

\section{RESULTS AND DISCUSSION}

\section{A. Electrical properties}

Fig. 5 shows the electrical properties of the fabricated planar power inductors, (a) is the inductance and quality factor v.s. frequency, and (b) is the superimposed dc current characteristic of inductance. Experimental data of air-core inductor are also shown in the figure.
As shown in Fig. 5(a), Type A and B inductors exhibited 10 $\mathrm{nH}$ inductance which was 3.4 times higher than that of aircore value. Quality factor of two inductors was about 20 at $100 \mathrm{MHz}$, which was comparable with air-core value.

As shown in Fig. 5(b), Type A inductor using Zn-ferrite core exhibited $17 \%$ degradation of inductance owing to the superimposed dc current of $2 \mathrm{~A}$. On the other hand, inductance of the Type B inductor using composite core was constant even at superimposed dc current of $2 \mathrm{~A}$, which was due to the low permeability magnetization curve shown in Fig. 3(a).

\section{B. Magnetic flux density distribution under superimposed dc current}

In order to investigate the magnetic flux density distribution of the magnetic core when flowing superimposed dc coil current, nonlinear magnetic field analysis (JMAG-Studio, JSOL Co.) was done, where nonlinear $B-H$ characteristic of the magnetic core was obtained from nonlinear $M-H$ curve measured by VSM, that is, $B=M+\mu_{o} H$.

Fig. 6 shows the magnetic flux density distribution of the magnetic core when superimposed dc current was $2 \mathrm{~A}$, (a) is in case of $10 \mu \mathrm{m}$ thick $\mathrm{Zn}$-ferrite film for Type A inductor, and (b) is in case of $50 \mu \mathrm{m}$ thick top composite film for Type $\mathrm{B}$ inductor. The maximum flux density $B_{\max }$ at $2 \mathrm{~A}$ superimposed dc current in Type A and B were $0.4 \mathrm{~T}(70 \%$ of saturation magnetic flux density $\left.B_{s}\right)$ and $0.14 \mathrm{~T}\left(25 \%\right.$ of $\left.B_{s}\right)$, respectively. From results of Fig. 5(b) and 6, it was considered that the Type A inductor with $10 \mu \mathrm{m}$ thick $\mathrm{Zn}$ ferrite core had a typical rating superimposed dc current of about 2 A.

On the other hand, since Type B inductor had low permeability composite thicker magnetic core, it exhibited enough margin for magnetic saturation even at superimposed $\mathrm{dc}$ current of $2 \mathrm{~A}$. However, superimposed dc current characteristic over $2 \mathrm{~A}$ is not shown in Fig. 5(b), this was owing to the increase of dc copper loss $\left(I_{d c}{ }^{2} R_{d c}, R_{d c}=50 \mathrm{~m} \Omega\right)$ with increasing $I_{d c}$. For example, when $I_{d c}$ is $5 \mathrm{~A}$, the dc copper loss becomes $1.25 \mathrm{~W}$ and will cause undesired temperature rise. For getting larger rating dc current, the dc resistance should be reduced as low as possible. 


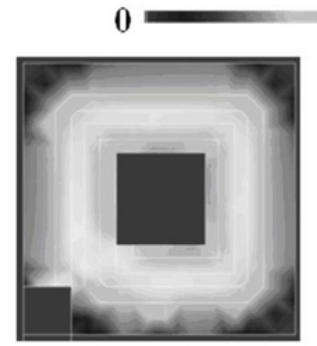

Type $\mathrm{A}$ inductor

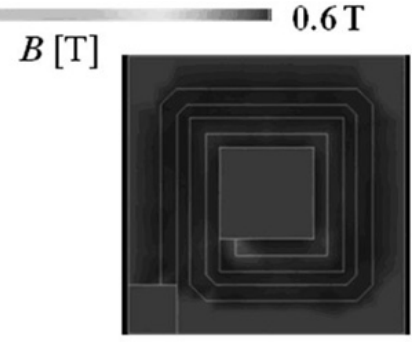

Type B inductor
Fig. 6 Magnetic flux density distribution in the magnetic core when superimposed dc current was $2 \mathrm{~A}$.

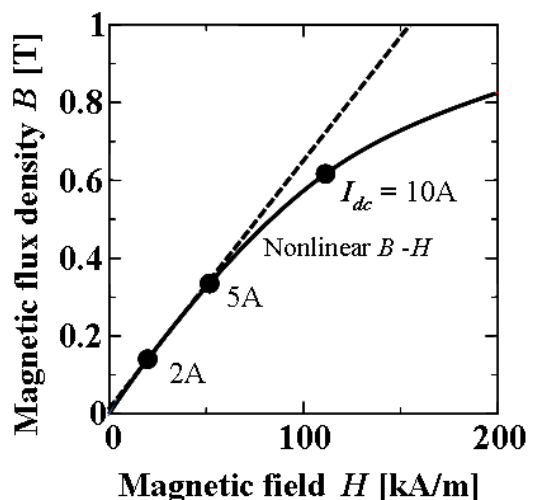

Fig. 7 Operation point on nonlinear $B-H$ curve v.s. superimposed dc current $I_{d c}$ of $50 \mu \mathrm{m}$ thick top composite core in Type B inductor, which was estimated by nonlinear magnetic field analysis.

Fig. 7 shows a predicted operation point on nonlinear $B-H$ curve v.s. superimposed dc current $I_{d c}$ in the $50 \mu \mathrm{m}$ thick top composite core of Type B inductor, which was estimated by nonlinear magnetic field analysis. In the figure, a broken line means a linear $B-H$ relation. Since the operation point for $I_{d c}$ of $5 \mathrm{~A}$ is on the linear $B-H$ relation, constant inductance will be kept at least up to $I_{d c}$ of $5 \mathrm{~A}$. If the lower dc coil resistance can be realized, Type B inductor will have 5 A rating current.

\section{CONCLUSION}

In order to investigate a possibility of planar power inductor embedded in package for hundreds megahertz switching dc-dc converter, two types of planar power inductors using Znferrite thick film and Fe-based amorphous/polyimide composite thick film have been fabricated and evaluated.

The fabricated inductors with $850 \times 850 \mu \mathrm{m}$ foot-print, 20 $\mu \mathrm{m}$ thick 2-turn copper spiral coil exhibited an inductance of $10 \mathrm{nH}$ and quality factor of 20 at $100 \mathrm{MHz}$. The rating superimposed dc current was at least up to 2 A. Especially, since the thicker composite magnetic core had the low permeability magnetization curve, the rating current of 2-turn spiral inductor is expected to be up to $5 \mathrm{~A}$ by introducing very low dc- resistance coil.

In the future, LSI-package TEG (Test Element Group) including the embedded planar power inductor will be developed and applied to hundreds megahertz switching dc-dc converter.

\section{ACKNOWLEDGMENT}

This work was supported in part by a Grant-in-Aid for Scientific Research of Japan Society for the Promotion of Science (JSPS), No. 20560321.

\section{REFERENCES}

[1] T. Yachi, M. Mino, A. Tago, and K. Yanagisawa, "A new planar micro transformer for use in micro-switching- converters", IEEE Power Electronics Specialists Conference 1991, pp. 20-26, (1991).

[2] T. Sato, H. Tomita, A. Sawabe, T. Inoue, T. Mizoguchi, M. Sahashi, “A magnetic thin film inductor and its application to a MHz switching dc-dc converter", IEEE Transactions on Magnetics, Vol.30, No.2, pp.217-223, (1994).

[3] T. Sato, E. Komai, K. Yamasawa, T. Hatanai, A. Makino, "Application of nanocrystalline $\mathrm{Fe}$ (or Fe-Co)-Hf-O magnetic films with high electrical resistivity to micro dc-dc converter", IEEE Transactions on Magnetics, Vol.33, No.5, pp.3310-3312, (1997).

[4] E. J. Brandon, E. Wesseling, V. White, C. Ramsey, L. Del Castillo, and U. Lieneweg, "Fabrication and characterization of microinductors for distributed power converters", IEEE Transactions on Magnetics, Vol.39, No.5, pp.2049-2056, (2003).

[5] S. Prabhakaran, C. R. Sullivan, T. O'Donnel, M. Brunet, and S. Roy, "Microfabricated coupled inductors for DC-DC converters for microprocessor power delivery", IEEE Power Electronics Specialists Conference 2004, pp. 4467-4472, (2004).

[6] D. S. Gardner, G. Schrom, F. Paillet, B. Jamieson, T. Karnik, and S. Borkar, "Review of On-Chip Inductor Structures with Magnetic Films", IEEE Transactions on Magnetics, Vol.45, No.10, pp.4760-4766 (2009).

[7] P. Hazucha, G. Schrom, J. Hahn, B. A. Bloechel, P. Hack, G. E. Dermer, S. Narendra, D. Gardner, T. Karnik, V.De, and S. Borkar, "A 233-MHz 80\%-87\% Efficient Four-Phase DC-DC Converter Utilizing Air-Core Inductors on Package", IEEE Journal of Solid-State Circuit, Vol.40, No.4, pp.838-845 (2005).

[8] K. Onizuka, K. Inagaki, H. Kawaguchi, M. Takamiya, and T. Sakurai, "Stacked-Chip Implementation of On-chip Buck Converter for Distributed Power Supply System in SiPs", IEEE Journal of Solid-State Circuits, Vol.42, No.11, pp.2404-2410, (2007).

[9] M. Abe, "Ferrite-Film Formation from an Aqueous Solution, and Its Application", Journal of the Magnetics Society Japan, Vol.22, No.9, pp.1225- 1232(1998) (in Japanese).

[10] A. Fujiwara, M. Tada, T. Nakagawa, and M. Abe: "Permeability and electric resistivity of spin-sprayed $\mathrm{Zn}$ ferrite films for high-frequency device applications", Journal of Magnetism and Magnetic Materials, Vol.320, No.8, pp.L67-69 (2008).

[11] I. Endo, I. Otsuka, R. Okuno, A. Shintani, M. Yoshino, M. Yagi, "Febased amorphous soft-magnetic powder produced by spinning water atomization process (SWAP)," IEEE Transactions on Magnetics, Vol.35, No.5, pp.3385-3387 (1999).

[12] M. Yamaguchi, Y. Miyazawa, and K.-I. Arai, "A New 1 MHz-9 GHz Thin-Film Permeameter Using a Side-Open TEM Cell and a Planar Shielded-Loop Coil", Transactions of the Magnetics Society of Japan, Vol. 3, No. 4, pp. 137-140 (2003). 